\title{
Comparison of the Tinetti and Short Physical Performance Battery test specificities for detecting neuromotor pathologies
}

\section{Comparativo da especificidade das escalas de Tinetti e Short Physical Performance Battery na detecção de patologias neuromotoras}

Kamilla Johnny Yoshii Lopes

Alessandro dos Santos Pin ${ }^{2}$

Rosangela Maria da Silva Miranda ${ }^{3}$

\section{Andrea Ghelfi ${ }^{4}$}

\section{Corresponding Author:}

Alessandro dos Santos Pin

Rodovia GO 320 s/n - Campus Universitário - Jd. Santa Paula. 75600-000 - Goiatuba - GO [Brazil]

keysersoze@bol.com.br
1 Federal University of Amazonas - UFAM. Coari, AM Brazil.

ORCID: https://orcid.org/0000-0001-7091-7218

2 Associated Professor - Physical Therapy Dept. - Goiatuba University Center - UNICERRADO. Goiatuba, GO/ Medicine Dept. - Mineiros University Center - UNIFIMES, Trindade, GO - Brazil.

ORCID: https://orcid.org/0000-0002-6005-7696

3 Federal University of Amazonas - UFAM. Coari, AM Brazil.

ORCID: https://orcid.org/0000-0002-8056-9701

4 Project Researcher - Kazusa DNA Research Institute - Japan ORCID: https://orcid.org/0000-0001-9617-3309

\begin{abstract}
Introduction: Increasing elderly populations require specific and accurate health assessment tools. Purpose: To compare the specificities of the short physical performance battery (SPPB) and the Tinetti Index validated in Brazil in patients with and without neuromotor dysfunctions. Materials and methods: Thirty-nine individuals (19 healthy and 20 with neuromotor changes) of both sexes aged 60-75 years, living in Coari (Amazonas state in Brazil), underwent SPPB and Tinetti scale assessments on alternate dates. Results and discussion: We observed significant differences between the scales, where the distribution was very concentrated after the Tinetti assessment and more dispersed after the SPPB in healthy individuals. This demonstrated that SPPB can detect minimal differences in gait and balance between healthy individuals, while the Tinetti scale is better at discriminating between healthy and those affected by mobility disorders. Conclusion: SPPB was more specific than the Tinetti Index in detecting changes in gait and balance.
\end{abstract}

Keywords: Gait. Postural Balance. Aged.

Resumo

Introdução: o aumento do público idoso nos serviços de saúde requer instrumentos de avaliação cada vez mais específicos e precisos no diagnóstico deles. Objetivo: comparar a especificidade da SPPB e Índice de Tinetti validadas no Brasil em pacientes com e sem disfunções neuromotoras. Materiais e Métodos: 39 sujeitos (19 saudáveis e $20 \mathrm{com}$ alterações neuromotoras) de ambos os sexos com idade entre 60 e 75 anos, residentes em Coari - AM, realizaram em datas alternadas avaliação pelas escalas SPPB e Tinetti. Resultados e discussão: foi observada diferença significativa entre as escalas, onde a distribuição mostrou-se muito concentrada em Tinetti e mais dispersa na SPPB para o grupo saudável, demonstrando que a SPPB conseguiu detectar as mínimas diferenças em marcha e equilíbrio entre indivíduos saudáveis; enquanto a escala de Tinetti discriminou melhor os indivíduos saudáveis dos patológicos. Conclusão: a SPPB mostrou-se mais específica que Tinetti, sendo capaz de detectar melhor alterações em marcha e equilíbrio.

Descritores: Marcha. Equilíbrio Postural. Idosos. 


\section{Introduction}

Human aging generates progressive morphological, physiological, biochemical and psychological changes that are part of the normal life cycle and are associated with the emergence of chronic degenerative diseases that may accelerate the functional decline of elderly individuals. Combinations of these factors compromise the performance in the elderly, causing loss of balance, impairment of visual, vestibular, proprioceptive, and somatosensory systems and postural control difficulties ${ }^{1}$.

Body balance is considered the most affected function during the aging process ${ }^{1}$. The prevalence of balance complaints in the population over 65 years of age reaches $85 \%$. Therefore, identifying balance and gait deficits as soon as they are apparent allows for preventive measures to be taken to avoid falls ${ }^{2}$.

Considering these factors, the interest in objective measures of functional balance has increased since the 1990s, and scales have been devised to measure balance, gait performance, risk of falling, and related variables during rehabilitation sessions. However, few studies have focused on these criteria, and their results are insufficient to support clinical decisions or to use as diagnostic tools when the functional balance is decreased ${ }^{3}$. Balance is assessed by a variety of tests that involve different protocols and methodologies ${ }^{4}$ and can be classified into static, timed, functional, subjective, and observational. Most of these tests have been chosen for their ease and low cost, but little is known about their correlations to each other ${ }^{4,5}$.

Given the importance of body balance evaluation, several instruments for evaluation of postural control have been developed during the search for clinical predictors of the risk of falls in the elderly. Among the clinical tests to assess balance, the most commonly used include the functional reach test (FRT), the Berg balance scale, the "Timed up and go "(TUG) test and the Tinetti balance test (or performance oriented mobility assessment, POMA) ${ }^{4,5}$, which have been validated in the original language and have good reliability.
Other evaluation scales and indexes for physical characteristics of the population with balance and gait deficits include the Berg scales, and the Tinetti, Katz and SPPB tests ${ }^{6}$.

The scale of Tinetti evaluates specific aspects of gait and balance, assigning a physical capacity score to the individual ${ }^{6}$, it is an established evaluation scale validated in Brazil in 2003, and is thought to be able to detect changes in balance and gait .

The short physical performance balance - SPPB test has been used on studies about aging, as a practical and effective tool to assess physical performance and to identify risks of future disability in elderly individuals. The test assesses three aspects of the performance of the lower limbs: muscle strength, gait, and balance (fundamental components for quality of life, accepted as universal health status indicators in the elderly) ${ }^{8}$. The test has been validated in Brazil (2007) ${ }^{6}$.

The SPPB scale proposed by Guralnik ${ }^{9}$ has demonstrated validity and reliability for functional capacity ratings and is useful for predicting early deterioration, institutionalization, and death; it shows sensitivity to changes and is applicability in diverse communities.

Since its validation in Brazil, the SPPB test has been used clinically on a large scale. But whether the SPPB test provides an advantage over the classical scales used in the evaluation of balance and falls that show high reliability indexes and sensitivities (such as the Tinetti scale) remains to be seen. The purpose of this study was to compare the specificities of the evaluations of healthy elderly individuals with neuromotor pathologies made by the SPPB and Tinetti scales. We suspected the SPPB scale would be more specific than the Tinetti scale due to greater detail in its application.

\section{Materials and methods}

This was a transversal study in which we selected individuals according to inclusion and exclusion criteria. We recruited participants from 
the Elderly Community Center in the city of Coari (Amazonas, Brazil) and the Physiotherapy Clinic of the Institute for Health and Biotechnology, Federal University of Amazonas (ISB - UFAM), who agreed to participate in the study and signed Free and Clear Consent Term (FCCT) forms approved by the Research Ethics Committee of the UFAM. The Coari city is located on the banks of the Solimões River, $363 \mathrm{~km}$ from the state capital, Manaus, and is located in the central region of the state of Amazonas (Brazil). According to the 2010 census, the city has a geographical area of $57,921.914 \mathrm{~km}^{2}$, and a low population density__1.3 persons $/ \mathrm{km}^{2}$. The total population recorded in the 2010 census was 75,965 inhabitants and of this total, $4.5 \%$ was made up of individuals above 60 years of age ${ }^{10}$. The city presented an HDI of 0.627 in 2000, while Brazil had an average HDI of 0.757. The inclusion factors required individuals to be between 60 and 75 years of age, to be residents of the city of Coari, to be free from uncontrolled chronic diseases (e.g. hypertension, diabetes mellitus), to be able to stand up, and to agree with the terms of the research (described in the FCCT) according to the ethical principles in Resolution 466/12 of the National Health Council. We excluded individuals unable to respond to the commands of the tests, those who had suffered fractures in the past two years, and had those who did not attended the data collection event. The Ethics Committee of UFAM approved this study with CAAE Number 13657313.8.0000.5020.

We conducted a Physiotherapy Clinic at ISB-UFAM as a pre-assessment evaluation to detect neuromotor injury cases across the sample universe with 103 elderly individuals (57 without cerebral injury and 46 with cerebral injury). After these evaluations, we classified individuals into two distinct groups according to the presence or absence of cerebral injury.

A researcher, blinded to the pre-assessment, selected twenty individuals of the group without injury for the $S$ group and 19 individuals with cerebral lesions for the P group. After assembly of the groups, we applied two functional performance tests validated for the Portuguese language (SPPB protocol ${ }^{6}$ and Balance Index and Tinetti Gait ${ }^{7}$ ) to each individual.

The SPPB evaluates three balancing positions: with feet together, semi-tandem, and tandem. Participants able to maintain the position with feet together and semi-tandem for 10 seconds are assigned 1 point, those who do not keep the position during this time or refuse to try, are not awarded points; participants able to hold the tandem position for 10 seconds are assigned 2 points; those remaining in position between 3 and 9.99 seconds are assigned 1 point, and to maintaining the position for a time less than 3 seconds are awarded no points. The total value of the balancing test is given by the sum of the three positions, with a maximum score 4 points. Gait velocity is assessed as follows: individuals are asked to walk with their usual step for a distance of 4 meters. Two walks are timed and the score is the time of the shorter walk. The maximum score is 04 points, the lower the speed, the lower the score. The lower limb strength test is performed with individuals sitting and standing up from their chair five times in a row, without using their upper limbs for support. The maximum score of the lower limbs strength test is 4 points. The scale evaluates all items from a score of 0 (worst performance) to 12 points (best performance). The test result may be graduated: zero to 3 points in cases of very poor performance; 4-6 points in cases of low performance; 7-9 points in cases of moderate performance; and 10-12 points in cases with good performance ${ }^{6}$.

The Tinetti test evaluates balance and gait abnormalities, it consists of 16 items, where nine are for body balance and seven for the gait. The Tinetti test classifies the aspects of balance (sitting, rising, standing and turning $360^{\circ}$ ) and also changes of position with eyes closed. During the gait evaluation the height and stride length, distance from the step, symmetry and continuity of steps, the ankle distance, and other variables are considered. The score for each exercise varies from $0-2$, where a lower score indicates a poorer physical ability. The total score (28 points) is the sum of body balance (16 points) and gait scores (12 points), the higher scores reflect better individual performances ${ }^{7}$. 
We applied the protocols for each test on alternate days, to avoid test outcome interference due to possible fatigue or muscle pain. We also respected the same place and application times, to eliminate biases from changing climate and environments. On the first day we started with the Tinetti Index and after 48 hours we applied the validated version for the Portuguese language SPPB.

We used descriptive statistics for data processing and analysis. We presented results as averages and standard deviations, or as absolute and percentage values as appropriate. We used the $\mathrm{R}$ Graphis program to further evaluate the data statistically: ANOVA multivariate test (for comparison between two variables in the same group and for comparison of the same variable between different groups); finally, we identified correlations between the gait and balance variables in Tinetti and SPPB tests. We considered $p$ $<0.05$ as statistically significant.

\section{Results}

The purpose of our research was to compare the specificities of SPPB and Tinetti scales for the evaluation of healthy elderly individuals with neuromotor pathologies.

From 39 participants, those who fit the criteria for the $S$ group $(n=20)$ had an average age of 69.6 years \pm 7.08 years, and included 14 (70\%) women and six men (30\%). On the other side, the individuals in the P group $(\mathrm{n}=19)$ had an average age of 72.21 years \pm 10.75 , and 10 (52\%) were men and $9(48 \%)$ women.

Table 1 lists the results of Tinetti and SPPB tests for groups $\mathrm{S}$ and $\mathrm{P}$.

Table 1: Tinetti and SPPB S and P groups mean scores

\begin{tabular}{c|c|c|c|c|c|c|c}
\hline Group & $\begin{array}{c}\text { TINETTI } \\
\text { Balance }\end{array}$ & $\begin{array}{c}\text { TINETTI } \\
\text { Gait }\end{array}$ & $\begin{array}{c}\text { TINETTI } \\
\text { Total }\end{array}$ & $\begin{array}{c}\text { SPPB } \\
\text { Balance }\end{array}$ & $\begin{array}{c}\text { SPPB } \\
\text { Gait }\end{array}$ & $\begin{array}{c}\text { SPPB } \\
\text { Chair }\end{array}$ & $\begin{array}{c}\text { SPPB } \\
\text { Total }\end{array}$ \\
\hline $\mathrm{S}(\mathrm{n}=20)$ & 15,65 & 11,5 & 27 & 3,35 & 2,5 & 2,35 & 8,2 \\
\hline $\mathrm{P}(\mathrm{n}=19)$ & 12,21 & 8,26 & 20,53 & 2,58 & 1,63 & 1,10 & 5,37 \\
\hline
\end{tabular}

Authors data.
Table 2 shows the sociodemographic and clinical data of the individuals in the study population. We found no correlation between the items evaluated and the results of the tests.

Table 2: Sociodemographic and clinical data of elderly in the city of Coari-AM

\begin{tabular}{|c|c|c|}
\hline Variables & Number (n) & $\%$ \\
\hline \multicolumn{3}{|c|}{ Sex } \\
\hline Male & 16 & 41,03 \\
\hline Female & 23 & 58,97 \\
\hline \multicolumn{3}{|c|}{ Marital status } \\
\hline Married/ with a partner & 20 & 51,28 \\
\hline Without a partner & 19 & 48,72 \\
\hline \multicolumn{3}{|c|}{ Occupational situation } \\
\hline Retired / Pensioner & 33 & 84,62 \\
\hline Unemployed & 1 & 2,56 \\
\hline Active & 5 & 12,82 \\
\hline \multicolumn{3}{|c|}{ Education } \\
\hline Illiterate & 17 & 43,59 \\
\hline Elementary School & 20 & 51,28 \\
\hline High school & 2 & 5,13 \\
\hline \multicolumn{3}{|c|}{ Clinical Onsets * pathological group } \\
\hline AVC/AVE & 8 & 42,10 \\
\hline Parkinson & 6 & 31,59 \\
\hline Alzheimer & 4 & 21,05 \\
\hline Polyneuropathy & 1 & 5,26 \\
\hline
\end{tabular}

Authors data.

The SPPB test proved more sensitive than the Tinetti test, because it uncovered minimal gait and balance disturbances that were not identified by the Tinetti test (Figure 1).

We found a correlation between balance, gait, and strength of the lower limbs in the SPPB test and the balance and gait in the Tinetti test, but when the balance results in the SPPB test were compared to those in the Tinetti test, the correlation disappeared, the same applied to the gait evaluation.

The Tinetti test showed more clear differences between individuals with gait disturbances and those without them than the SPPB test, 


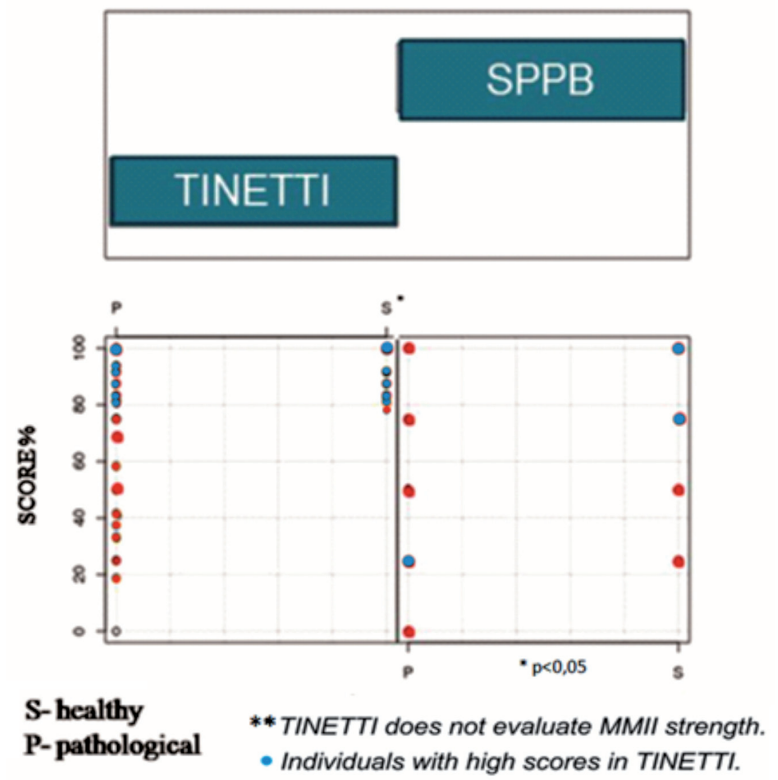

Figure 1: Distribuition of scores Tinetti and SPPB

Authors data.

but this last one was able to uncover smaller motor behavior differences (Figure 2).

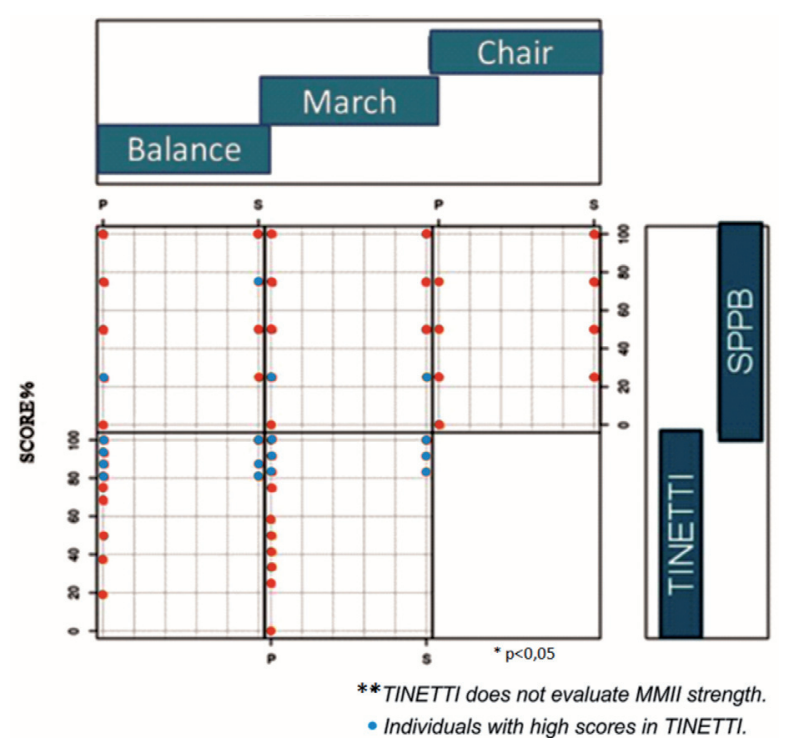

Figure 2: Interaction between the strands Authors data.

We left the lower limbs' strength out of the analysis in SPPB, and we found no statistical difference when compared to the overall evaluation (Figure 3).

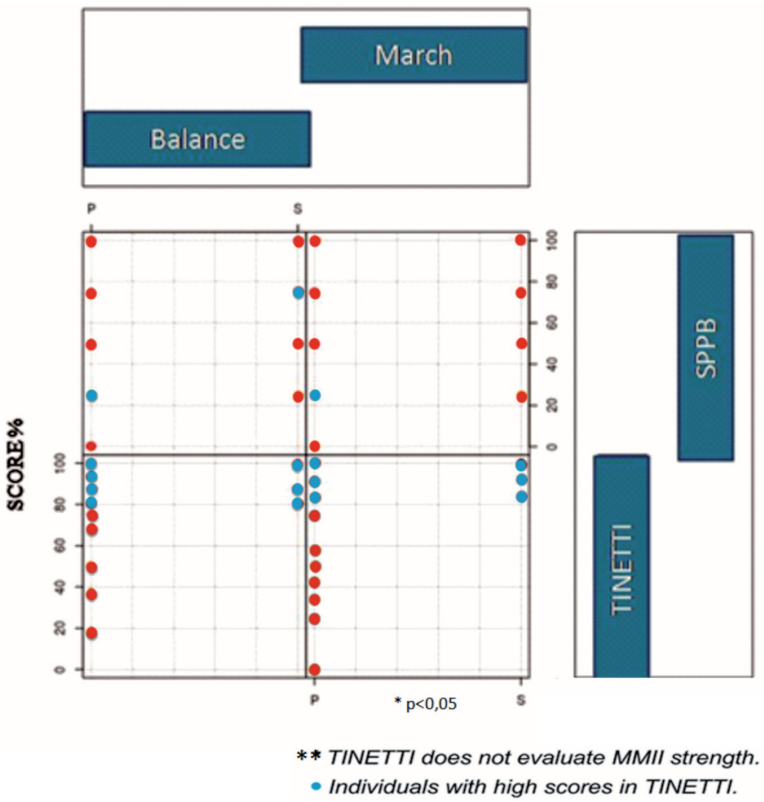

Figure 3: Interaction between the strands Authors data.

\section{Discussion}

Different methods can be used to evaluate the postural balance and identify the nervous system adaptations for maintaining stable postures, which probably do not produce the same effect of sensory disturbance. Other studies have compared the results of balance tests reflecting different proprioceptive disturbances. However, whether different methods identify similar proprioceptive disorders, allowing for comparisons between groups or experimental conditions is unclear ${ }^{11}$.

The evidence in the literature suggests the existence of a positive correlation between equilibrium and gait tests, and these are considered complementary to each other, requiring their joint application to evaluate balance in the elderly population ${ }^{1,4,11,12,13}$.

Among the many balance and gait scales, SPPB and Tinetti are some of the most reliable and valid. Although the SPPB application time is the highest of all the tests, the reliability of its results was found to be higher than those of all the other tests analyzed ${ }^{14}$. Our results showing 
the higher diagnostic specificity of SPPB than that of the Tinetti test, suggest a clinical advantage with the adoption of the SPPB as a standard clinical evaluation instrument.

We found a higher specificity for SPPB than for Tinetti results. The SPPB scale presented more dispersed scores for the two groups than the Tinetti scale, reflecting better resolution of the differences in the physical quality of gait and balance of the groups. By contrast, the Tinetti scale showed a higher concentration in high scores for the healthy group. Thus, some individuals screened as requiring intervention by the SPPB test, were regarded as normal according to their Tinetti results.

After comparing gait and balance questions within the same tests, Nakano found a strong correlation between the scores of the balance and gait domains. ${ }^{6}$ Another study found no significant correlations between gait velocity and balance, and suggested that the gait velocity could decline independently of the balance level of an individual ${ }^{15}$. In our study, we found a positive correlation between balance, gait, and lower limb strength according to SPPB results, and between balance and gait according to Tinetti results.

When comparing the same variables between different tests, Karuka et al presented a positive correlation between the Berg balance scale (BSE) scores and those of the Tinetti test. ${ }^{11}$ In our study, the comparison between the SPPB balance and the Tinetti equilibrium yielded a negative correlation, i.e. individuals who achieved high equilibrium performance in Tinetti did not repeat it in SPPB, the same was true for gait scores.

The reliability of the SPPB scale has been confirmed by studies that showed correlations between pathological situations and the test scores. ${ }^{16,17,18,19,20}$ This reinforces the validity of our results confirming the advantage of the SPPB evaluation for the sample.

In this study, the Tinetti scale was able to differentiate well the individuals in the $S$ and $P$ groups (higher $\mathrm{S}$ score), while the SPPB test presented scattered scores for both groups, and it was impossible to differentiate individuals between the groups based on the test scores alone. However, as the individuals in the $\mathrm{P}$ group did not present the same degree of impairment, the SPPB was more specific for detecting performance decreases as evidenced by the gait and balance quality score dispersion. The SPPB was able to detect small differences in the quality of gait and balance that remained unidentified by the Tinetti test, indicating the greater reliability of the SPPB test for clinical evaluations in similar populations.

This is the first study comparing the SPPB and the Tinetti tests. However, we are aware of its limitations, specially the fact that we carried out the study with a specific population, in a restricted location; and, thus, our results cannot be extrapolated to any population.

\section{Conclusion}

We found the SPPB to be more specific than the Tinetti test in our population, due to the significant difference in scores obtained between the groups of individuals (we found major differences between the results of gait and balance in both groups), with a difference in the physical quality of the individual in gait and balance. The SPPB test was able to detect smaller differences in gait and balance quality than the Tinetti test.

\section{References}

1 Esquenazi D, Silva SRB, Guimarães MAM. Aspectos fisiopatológicos do envelhecimento humano e quedas em idosos. Revista HUPE, Rio de Janeiro, 2014; 13(2):11-20

2 Fhon JRS et al. Prevalência de quedas de idosos em situação de fragilidade. Revista de Saúde Pública, 2013; 47(2):266-273.

3 Castro PMMA, Magalhães AM, Cruz ALC, Reis NSRD. Testes de equilíbrio e mobilidade funcional na predição e prevenção de riscos de quedas em idosos. Rev Bras Geriatr Geront, 2015; 18(1):129-140. 
4 Ansai JH et al. Revisão de dois instrumentos clínicos de avaliação para predizer risco de quedas em idosos. Rev Bras Geriatr Geront, 2014; 17(1):177-189 .

5 Ferreira LMBM, Jerez-Roig J, Andrade FLJP, Oliveira NPD, Araújo JRT, Lima KC. Prevalência de quedas e avaliação da mobilidade em idosos institucionalizados. Rev Bras Geriatr Gerontol, 2016; 19(6):995-1003

6 Nakano MM. Versão Brasileira da Short Physical Performance Battery - SPPB: Adaptação cultural e estudo da confiabilidade. [Thesis]. Campinas (SP): UNICAMP, Faculdade de Educação, 2007.

7 Gomes C. Tradução, Adaptação Transcultural e Exame das propriedades de Medida da Escala Performance-Oriented Mobility Assessment (POMA) Para Uma Amostragem De Idosos Brasileiros Institucionalizados. [Dissertação]. Campinas (SP): UNICAMP, 2003.8 - Marchon RM, Cordeiro RC, Nakano MM. Funtional capacity of elderly people living in a long-term care facility: a prospective study. Rev Bras Geriatr Gerontol, 2010; 13(2):203-214.

9 Guralnik JM, et al. Lower-Extremity Function in Persons over the Age of 70 Years as a Predictor of Subsequent Disability. N Engl J Med, 1995; 332 (9): 556-62.

10 Instituto Brasileiro de Geografia e Estatística. IBGE. Banco de dados: cidades@: Amazonas: Coari [documento da internet]. Disponível em: http:// www.ibge.gov.br/cidadesat/topwindow.htm?1 Brasil, 2011. Acesso em 21/12/2011.

11 Karuka AH, Silva JAMG, Navega MT. Análise da concordância entre instrumentos de avaliação do equilíbrio corporal em idosos. Analysis of agreement of assessment tools of body balance in the elderly. Rev Bras Fisioter, 2011; nov./dez; 15( 6): 460-6.

12 Sousa LMM et al. Instrumentos de avaliação do risco de quedas em idosos residentes na comunidade. Enferm Global, 2016; 42:506-21.
13 Bloem BR, Marinus J, Almeida Q, Dibble L, Nieuwboer A, Post B, et al. Measurement instruments to assess posture, gait, and balance in Parkinson's disease: critique and recommendations. Mov Disord, 2016; 31:1342-55.

14 Menezes KVRS, Auger C, Menezes WRS, Guerra RO. Instruments to evaluate mobility capacity of older adults during hospitalization: A systematic review. Arch Geriatr Geront, 2017; 72:67-79.

15 Abreu SSE, Caldas CP. Gait speed, balance and age: a correlational study among elderly women with and without participation in a therapeutic exercise program. Rev Bras Fisioter, 2008; 12 (4): 324-30.

16 Lourenço MA, Roma I, Assis MR. Correlação entre instrumentos de avaliação da funcionalidade e equilíbrio em pacientes com artrite reumatoide. Revista Brasileira de Educação Física e Esporte, 2015; 29(3): 345-353.

17 Paz LPS, Borges LL, Marães VRFS, Gomes MMF, Bachion MM, Menezes RL. Fatores associados a quedas em idosos com catarata. Ciênc Saúde Coletiva, 2018; 23(8):2503-2514.

18 Lauretani F, Ticinesi A, Gionti L, Prati B, Nouvenne A, Tana C, Meschi T, Maggio M. Short-Physical Performance Battery (SPPB) score is associated with falls in older outpatients. Aging Clin Exp Res, 2018; 4. doi: 10.1007/s40520-018-1082-y.

19 Rabini A, De Sire A, Marzetti E, Gimigliano R, Ferriero G, Piazzini DB, Iolascon G, Gimigliano F. Effects of focal muscle vibration on physical functioning in patients with knee osteoarthritis: a randomized controlled trial. Eur J Phys Rehabil Med, 2015; 51(5): 513-20.

20 Buckinx F, Croisier JL, Reginster JY, Petermans $\mathrm{J}$, Goffart E, Bruyère $\mathrm{O}$. Relationship between Isometric Strength of Six Lower Limb Muscle Groups and Motor Skills among Nursing Home Residents. J Frailty Aging, 2015; 4(4): 184-7 